\title{
Failure of SiC Particulate-Reinforced Metal Matrix Composites Induced by Laser Thermal Shock
}

\author{
Y.C. ZHOU, Z.P. DUAN, and Q.B. YANG \\ Thermal failure of $\mathrm{SiC}$ particulate-reinforced 6061 aluminum alloy composites induced by both laser \\ thermal shock and mechanical load has been investigated. The specimens with a single-edge notch \\ were mechanically polished to $0.25 \mathrm{~mm}$ in thickness. The notched-tip region of the specimen is \\ subjected to laser beam rapid heating. In the test, a pulsed Nd:glass laser beam is used with duration \\ $1.0 \mathrm{~ms}$ or $250 \mu \mathrm{s}$, intensity 15 or $70 \mathrm{~kW} / \mathrm{cm}^{2}$, and spot size $5.0 \mathrm{~mm}$ in diameter. Threshold intensity \\ was tested and fracture behavior was studied. The crack-tip process zone development and the mi- \\ crocrack formation were macroscopically and microscopically observed. It was found that in these \\ materials, the initial crack occurred in the notched-tip region, wherein the initial crack was induced \\ by either void nucleation, growth, and subsequent coalescence of the matrix materials or separation \\ of the $\mathrm{SiC}$ particulate-matrix interface. It was further found that the process of the crack propagation \\ occurred by the fracture of the $\mathrm{SiC}$ particulates.
}

\section{INTRODUCTION}

Over the last decade, the desire for lighter materials with high specific strength and stiffness has led to the development of a range of composite materials as serious alternatives to traditional engineering alloys. Particular interest in the aerospace industry has been directed toward ceramic-reinforced metal matrix composites (MMCs). For applications where high strength and modulus are required, especially at elevated temperatures, for example, in aeroengines, interest has centered around continuous fiber-reinforced titanium alloys. ${ }^{[1]}$ Where less extreme properties are required, however, lower cost aluminum matrix reinforced with a discontinuous phase in the form of particles or whiskers has been the subject of increasing investigation. ${ }^{[2,3,4]}$ These materials have the additional advantages of superior mechanical properties (such as high specific elastic modulus, high specific yield strength, and good wear resistance) and alloying fabrication by conventional metallurgical and mechanical processes..$^{[5,6]}$ In this area, $\mathrm{SiC}$ has become the main candidate for use as a reinforcing material. $\mathrm{SiC}$ exhibits good thermal conductivity and chemical compatibility with aluminum, forming an adequate bond with the matrix, without developing embrittling intermetallic phases if long periods of liquid metal contact are avoided, e.g., by powder or spray forming, ${ }^{[7]}$ and thereby offering significant advantages over competitors such as boron, graphite, and alumina.

However, it is well known that in aerospace engineering, many structural components are subject to severe thermal loadings that may be produced by aerodynamic heating, by laser irradiation, or by localized intense fire. ${ }^{[8,9]}$ Thermal shock may give rise to intense thermal stresses in the com-

Y.C. ZHOU, Professor, is with the Department of Physics, Xiangtan University; also with the Laboratory for Laser and Dynamic Behaviors of Materials, Institute of Mechanics, CAS. Z.P. DUAN, Professor, is with the Laboratory for Laser and Dynamic Behaviors of Materials, Institute of Mechanics, CAS, Beijing 100080, People's Republic of China. Q.B. YANG, Professor, is with the Department of Physics, Xiangtan University, Xiangtan 411105, Hunan, People's Republic of China.

Manuscript submitted March 25, 1997. ponents around cracks and other kinds of defects and especially in the components of ceramic-reinforced MMCs as a result of the thermoelastic mismatch in the metal and ceramic. The concentration of thermal stresses around defects often results in catastrophic failure. The development of a general methodology for durability and damage analysis for aerospace structures exposed to intense thermal shock will require a materials property database at elevated temperatures, a fracture mechanics solution technique for determining thermal stress intensity factor, and studies of fracture behavior ${ }^{[9,10,11]}$ Although the problem is very complicated, the present investigation experimentally examines the fracture behavior of $\mathrm{SiC}$ particulate-reinforced 6061 aluminum alloy under laser thermal shock.

\section{EXPERIMENTAL PROCEDURE}

\section{A. Thermal Shock System}

Thermal shock is generated by an incident laser beam that impinges normally to a single-edge notched specimen. The energy of the laser beam ranges from 1 to $5 \mathrm{~J}$, with an intensity of the order of $1.0 \times 10^{4}$ to $9.0 \times 10^{4} \mathrm{~W} / \mathrm{cm}^{2}$. It is a single pulse Nd:glass laser with a wavelength of 1.06 $\mu \mathrm{m} .{ }^{[12]}$ The diagnostics of the laser parameters provide a traditional monitoring of the laser beam characteristics, such as energy, temporal, and spatial shapes. A photoelectric cell with the corresponding response time of less than $1.0 \mathrm{~ns}$ was used to measure the temporal shape of the laser beam. The spatial shape of the laser intensity was detected by a charge-coupled device sensor. In the experiment, the temperature rise on the rear surface was measured using a focused, imaging system of infrared detectors, ${ }^{[13]}$ of which the focusing system was designed to be different from that used by Hartley et al. ${ }^{[14]}$ and Zehnder and Rosakis. ${ }^{[15]}$ The detailed information on the temperature measurement will be given elsewhere.

In the experiment, the pulsed Nd:glass laser beam with a full width at half of the maximum (FWHM) of $1.0 \mathrm{~ms}$ or $250 \mu \mathrm{s}$ is used to generate the thermal shock. Displayed in Figures 1(a) and 1(b) are the normalized intensity $I / I_{\max }$ with 


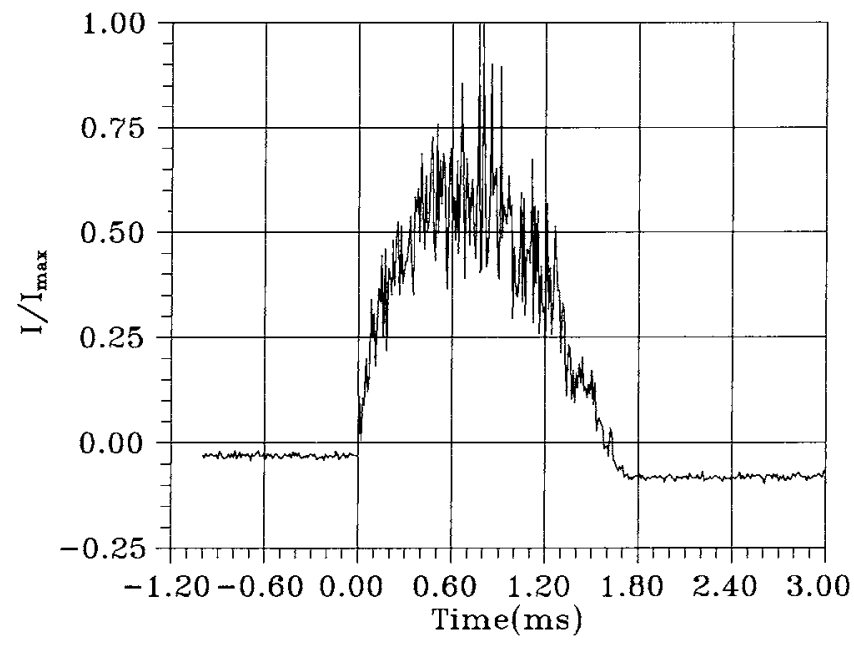

(a)

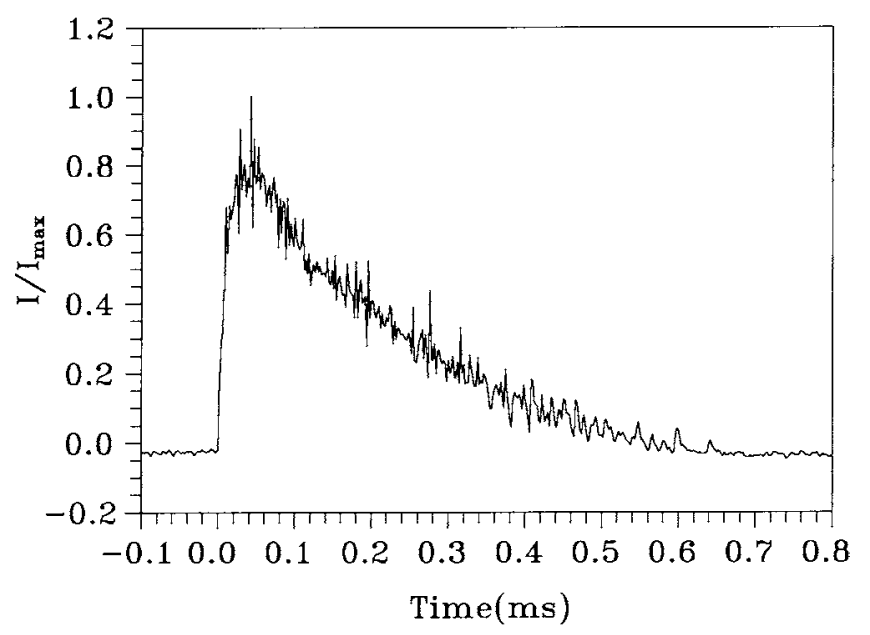

(b)

Fig. 1-Temporal shape of Nd:grass pulsed laser intensity: (a) $1.0 \mathrm{~ms}$ FWHM laser beam and (b) $250 \mu$ s FWHM laser beam.

time for $1.0 \mathrm{~ms}$ FWHM and $250 \mu \mathrm{s}$ FWHM, respectively. The normalized intensity $I / I_{\max }$ with space coordinates $r / a$ is shown in Figure 2, where $r$ and $a$ are the radial distance and the radius of the laser spot, respectively. The spatial distribution of the laser intensity is non-Gaussian, but roughly uniform within the laser irradiated region, and declines very sharply toward the edge where the laser spot terminates. For the convenience of numerical analysis, the laser intensity $I$ is approximated by

$$
I=I_{\max } e^{-\alpha t}\left(1-e^{-B t}\right) f(r)=I_{\max } g(t) f(r)
$$

where $\alpha$ and $\beta$ are experimentally determined and equal to $1.5 \times 10^{4} / \mathrm{s}$ and $8.0 \times 10^{4} / \mathrm{s}$, respectively. Therefore, the laser energy $E_{J}=\beta \pi a^{2} I_{\max } \alpha(\alpha+\beta)$ and we have

$$
f(r)=\left\{\begin{array}{l}
1, \text { if } 0 \leq r \leq a \\
0, \text { if } a<r<\infty
\end{array}\right.
$$

and $f(r)=e^{-(r / a)^{2}}$ to account for the non-Gaussian and Gaussian nature of the laser beam, respectively. As shown in our previous investigation, ${ }^{[9,27,28]}$ the laser beam with different spatial distributions will produce different damage modes.

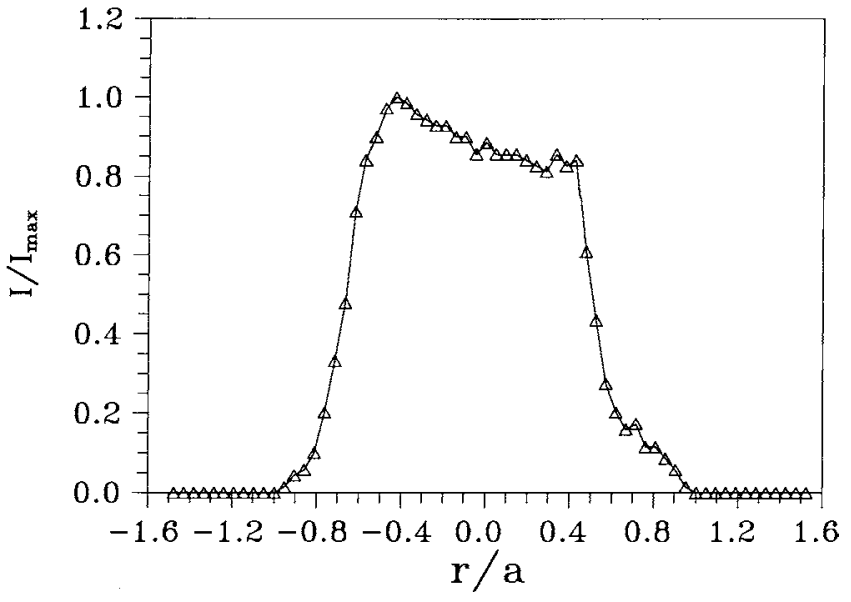

Fig. 2-Spatial shape of Nd:grass pulsed laser intensity.

Table I. Material Properties

\begin{tabular}{lcccc}
\hline \multicolumn{1}{c}{ Parameters } & Unit & $\begin{array}{c}\mathrm{Al} \\
\text { Matrix }\end{array}$ & $\begin{array}{c}\mathrm{SiC} \\
\text { Particle }\end{array}$ & Composite \\
\hline $\begin{array}{l}\text { Young's modulus } \\
\text { Yield strength }\end{array}$ & $\mathrm{GPa}$ & 68.3 & 427 & - \\
$\begin{array}{l}\text { Poisson's ratio } \\
\text { Thermal expansion }\end{array}$ & - & 0.33 & 0.17 & - \\
$\quad$ coefficients & $\times 10^{-6 /{ }^{\circ} \mathrm{C}}$ & 23.6 & 4.3 & - \\
$\begin{array}{l}\text { Thermal conductility } \\
\quad \text { coefficients }\end{array}$ & $\mathrm{W} / \mathrm{cm} \mathrm{K}^{3}$ & 1.8 & 0.42 & 1.206 \\
$\begin{array}{l}\text { Density } \\
\begin{array}{l}\text { Specific heat } \\
\text { capacity }\end{array}\end{array}$ & $\mathrm{g} / \mathrm{cm}^{3}$ & 2.7 & 2.65 & 2.69 \\
\hline
\end{tabular}

However, in this study, the laser beam with the non-Gaussian spatial shape results in the distinct stress distributions, as analyzed in the Section IV.

\section{B. Specimen Preparation and Description of the Problem}

$\mathrm{SiC}$ particulate/6061 Al composite is chosen as a model MMC system for this study, and its material properties are given in Table I. ${ }^{[6,25,26]}$ The composites with 15 wt pet $\mathrm{SiC}$ were fabricated by a melt casting route, and as-cast ingots of the composite were subsequently extruded. As-extruded $\mathrm{SiC} / \mathrm{Al}$ composites were all solution treated at $530{ }^{\circ} \mathrm{C}$ and then quenched from $530{ }^{\circ} \mathrm{C}$ to room temperature. The samples were cut from the hot-pressed billets with dimensions of $20 \times 8 \times 0.25 \mathrm{~mm}$. The test samples were the singleedge notched specimen and were placed in the static tensile machine. So the thermal failure is induced by both laser thermal shock and far-field mechanical load. Figure 3 is a schematic of the specimen configuration and dimensions. The starter notch was made with an electric discharge machine, as shown in Figure 3. The rear surface of the notched specimen, was polished and examined using both optical microscopy and scanning electron microscopy (SEM), and the front surface of the specimen was irradiated by the laser beam. The notched-tip region is subjected to laser beam heating (Figure 3(b)). 


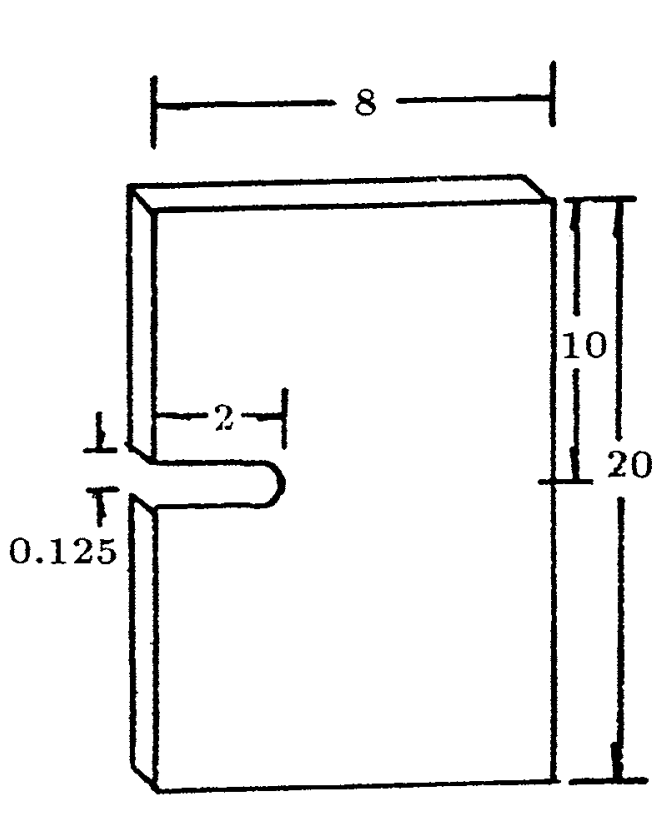

(a)

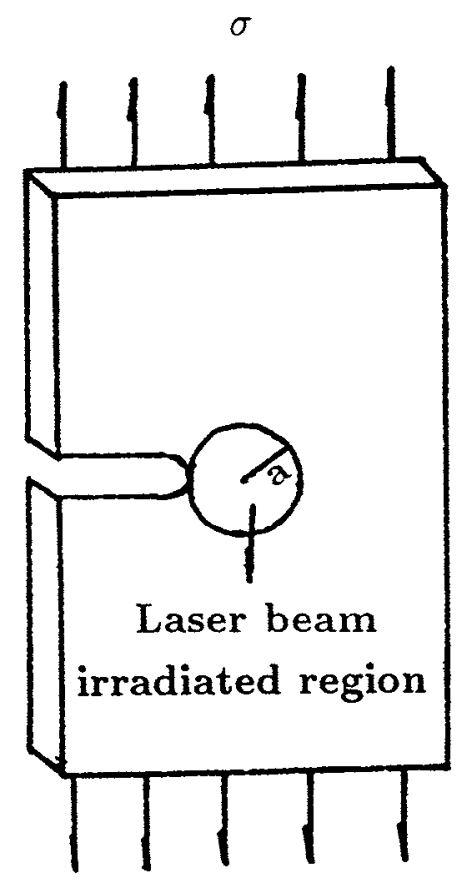

(b)

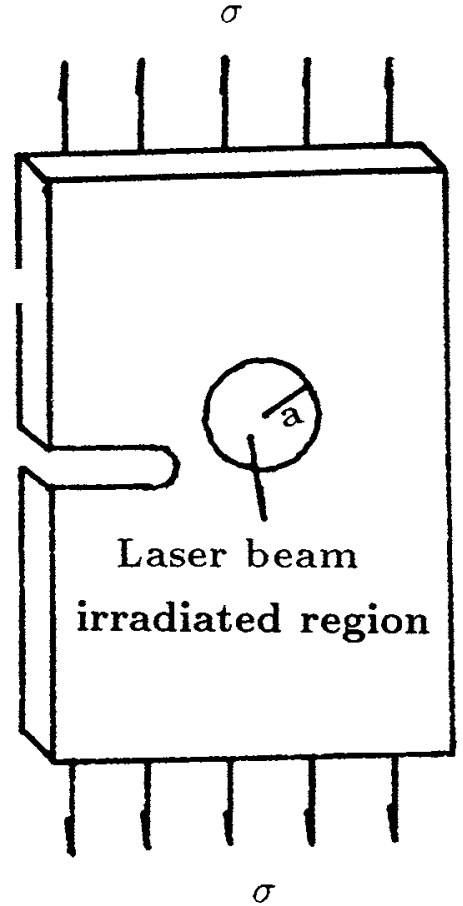

(c)

Fig. 3-Specimen configuration: $(a)$ the dimensions of the single edge notched specimen; $(b)$ the notched-tip region subjected to laser beam heating; and (c) the laser irradiated region away from the notched-tip region.

\section{EXPERIMENTAL RESULTS}

\section{A. Macrophenomena and Threshold Intensity}

The macrophenomena and threshold intensity are given in Table II for the thermal failure of SiC particulate-reinforced 6061 aluminum alloy composites induced by both laser thermal shock and far-field mechanical load. The mechanical load is tensile stress of $36.7 \mathrm{MPa}$, and the laser spot size is $5.0 \mathrm{~mm}$ in diameter. According to the test data given in Table II, when only the mechanical loading exists and the laser beam thermal shock is absent, no visible macroscopic damage is observed on the rear surface of the specimen. On the other hand, when the laser energy density is lower than 10.8 and $14 \mathrm{~J} / \mathrm{cm}^{2}$ for $1.0 \mathrm{~ms}$ and $250 \mu \mathrm{s}$ FWHM laser beam, respectively, and the mechanical tensile stress is $36.7 \mathrm{MPa}$, we do not observe the macroscopic damage on the rear surface of the specimen. When the laser energy density is gradually increased, the damage is more and more serious. The specimen is totally fractured as the laser energy density is increased to 17.2 and $22.3 \mathrm{~J} / \mathrm{cm}^{2}$ for $1.0 \mathrm{~ms}$ and $250 \mu \mathrm{s}$ FWHM laser beam, respectively. It is noted that the laser intensity threshold value $I_{c r}$ for the specimen fractured is different for $1.0 \mathrm{~ms}$ and $250 \mu \mathrm{s}$ FWHM laser beam. In this case, the other parameters, such as specimen dimensions, laser spot, and mechanical loading, are the same.

\section{B. Deformation and Damage Initiation}

\section{Metallography of composites}

Typical microstructures prior to deformation and from the thermally deformed samples are, respectively, shown in Figures 4(a) and 4(b). Figure 4(a) shows that SiC particulates with average size $10 \mu \mathrm{m}$ are distributed uniformly throughout the aluminum matrix. This uniformity of microstructure is believed to be responsible for the isotropic nature of mechanical properties. ${ }^{[16]}$ It is also noted in Figure 4(a) that the $\mathrm{SiC}$ particulates are of angular shape. From the comparison between Figures 4(a) and 4(b), one can obviously observe that the matrix around the $\mathrm{SiC}$ particles is polished in Figure 4(a) and the matrix around the SiC particles is rough in Figure 4(b). The significance of the roughness is that there is apparent deformation induced by the laser heating. The surface is either relief or roughness as a consequence of the local deformation around the particles. It appears that the macroscopic surface has curvature and that is the reason that only a small region is in focus.

\section{Damage initiation and radial crack}

Figure 5 shows the SEM of microvoids in the notchedtip region with a laser energy density of $13.4 \mathrm{~J} / \mathrm{cm}^{2}$ and FWHM of $1.0 \mathrm{~ms}$. It is observed that the voids occur in the form of interfacial debonding between the particles and the matrix. In order to understand the initial damage behavior of $\mathrm{SiC}$ particulate-reinforced 6061-Al matrix composite induced by laser beam thermal shock, the laser beam irradiated region deviates from the notched-tip region, as shown in Figure 3(c). In this case, the radial crack appeared around the periphery of the laser beam, as shown in Figure 6 . The radial crack occurs by the void nucleation and growth within the matrix and decohesion at the interface between the particle and the matrix. Little SiC particle fracture is observed in Figure 6. When the reinforcement $\mathrm{SiC}$ particle is at the crack tip, the $\mathrm{SiC}$ particle does not fracture and resist the crack propagation. One can conclude that the initial damage may be produced in the form of the separation of the $\mathrm{SiC}$ particle-matrix interface or in the form of void nucleation and growth within the matrix. The onset 
Table II. Macrophenomena and Threshold Intensity

\begin{tabular}{|c|c|c|c|c|c|c|c|}
\hline Number & FWHM & $\begin{array}{c}\text { Energy } E_{J} \\
(\mathrm{~J})\end{array}$ & $\begin{array}{c}\text { Laser Spot } \\
\text { Diameter }(\mathrm{mm})\end{array}$ & $\begin{array}{l}\text { Energy Density } \\
\qquad\left(\mathrm{J} / \mathrm{cm}^{2}\right)\end{array}$ & $\begin{array}{l}\text { Intensity } \\
\left(\mathrm{kW} / \mathrm{cm}^{2}\right)\end{array}$ & $\begin{array}{l}\text { Static Tensile } \\
\text { Stress }(\mathrm{MPa})\end{array}$ & Macrophenomena \\
\hline 4 & & 0 & & 0 & 0 & 36.7 & (a) \\
\hline 5 & $1.0 \mathrm{~ms}$ & 2.13 & 5.0 & 10.8 & 10.8 & 36.7 & (a) \\
\hline 7 & $1.0 \mathrm{~ms}$ & 2.63 & 5.0 & 13.4 & 13.4 & 36.7 & (b) \\
\hline 6 & $1.0 \mathrm{~ms}$ & 3.13 & 5.0 & 15.9 & 15.9 & 36.7 & (c) \\
\hline 8 & $1.0 \mathrm{~ms}$ & 3.38 & 5.0 & 17.2 & 17.2 & 36.7 & (d) \\
\hline 9 & $250 \mu \mathrm{s}$ & 2.75 & 5.0 & 14.0 & 56.0 & 36.7 & (a) \\
\hline 10 & $250 \mu \mathrm{s}$ & 2.88 & 5.0 & 14.6 & 58.6 & 36.7 & (e) \\
\hline 11 & $250 \mu \mathrm{s}$ & 3.50 & 5.0 & 17.8 & 71.3 & 36.7 & (f) \\
\hline 12 & $250 \mu \mathrm{s}$ & 4.40 & 5.0 & 22.3 & 89.1 & 36.7 & (d) \\
\hline
\end{tabular}

(a) No observable macrodamage.

(b) In the notched-tip region, the voids appear, which occur in the form of interfacial debonding between the particles and the matrix, as shown in Figure 5 .

(c) Macrocracking is observed in the notched-tip region and the macrocrack is $0.13 \mathrm{~mm}$ in length, as shown in Figure 7(a).

(d) The sample is totally fractured.

(e) The laser irradiated region is away from the notched-tip region, as shown in Figure 3(c). The radial cracks are observed around the periphery of the laser beam, as shown in Figure 7(a).

(f) Macrocracking is observed in the notched-tip region and macrocrack is $0.1 \mathrm{~mm}$ in length, as shown in Figure 6.

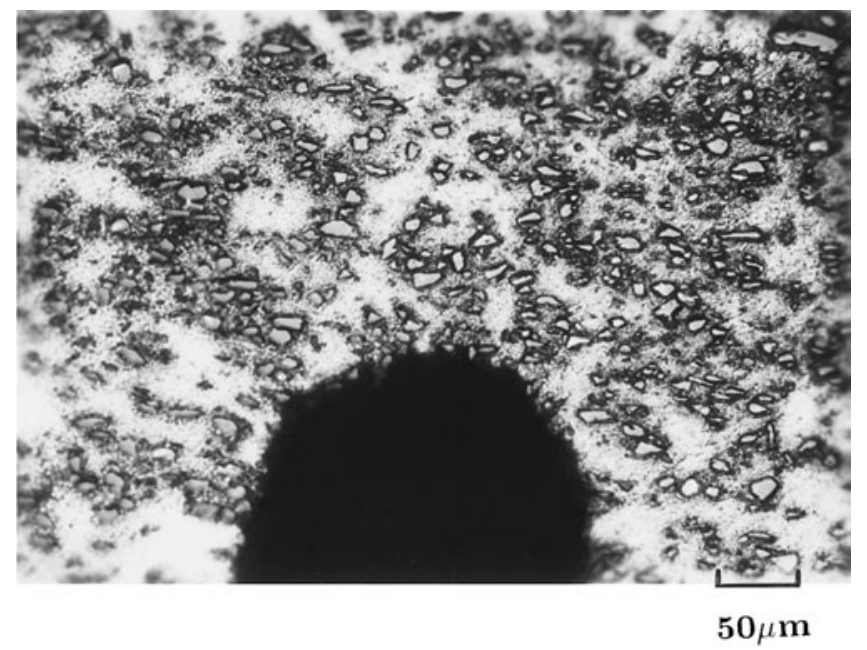

(a)

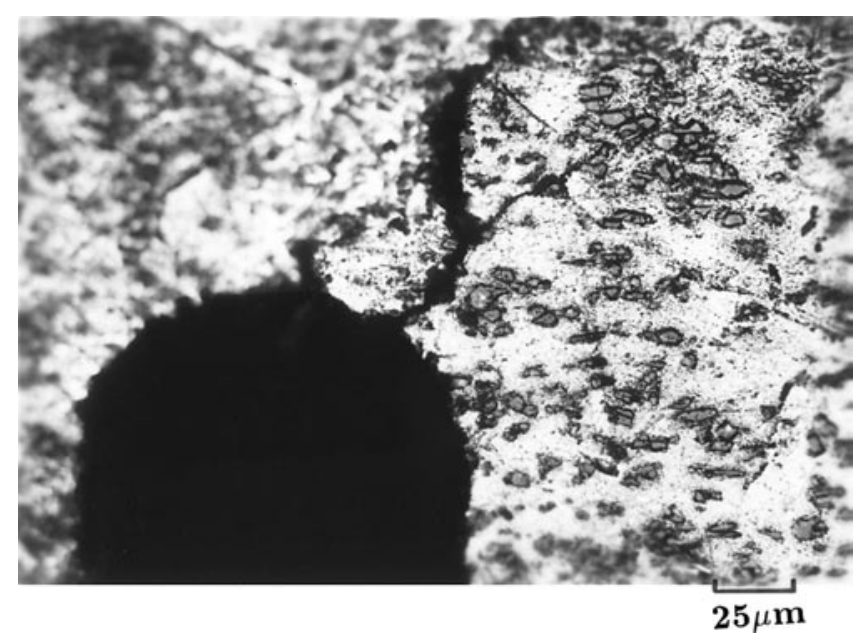

(b)

Fig. 4-Metallograph of composites: (a) original profiles of the notchedtip region and $(b)$ the front surface of the notched-tip region subjected to laser beam heating.

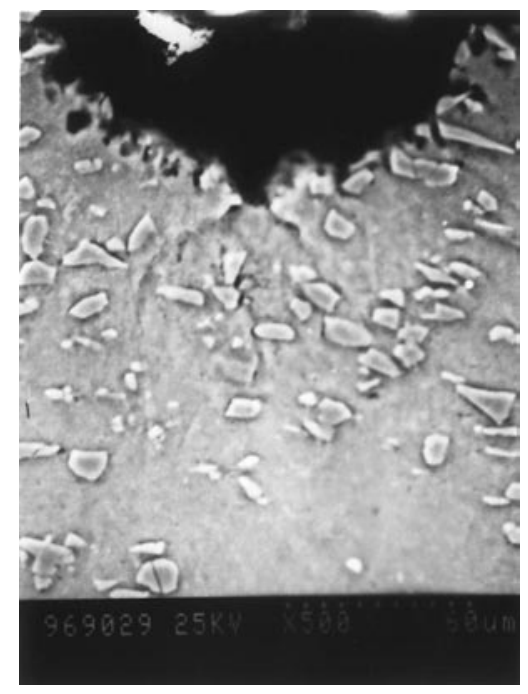

Fig. 5-SEM of microvoids in the notched-tip region with a laser energy of $2.63 \mathrm{~J}$ and $1.0 \mathrm{~ms}$ FWHM for sample 7 .

and progression of this ductile matrix failure are influenced by the development of local plastic strains and hydrostatic stresses during the coupled loading both with the laser thermal shock and the far-field mechanical load. The initial damage is similar to the fatigue fracture behavior. ${ }^{[17]}$

\section{Characteristic of microcracks and macrocrack}

When the energy density is increased to 15.9 and 17.8 $\mathrm{J} / \mathrm{cm}^{2}$ for $1.0 \mathrm{~ms}$ and $250 \mu \mathrm{s}$ FWHM laser beam, respectively, the microcracks formed in the notched region grew into macroscopic cracks. Low-magnification scanning electron micrographs of macrocracks in the notched-tip region are shown in Figure 7. This corresponded to a laser energy of $3.13 \mathrm{~J}$, an FWHM of $1.0 \mathrm{~ms}$, and an intensity of 15.9 $\mathrm{kW} / \mathrm{cm}^{2}$ for Figure 7(a) and a laser energy of $3.5 \mathrm{~J}$, an FWHM of $250 \mu \mathrm{s}$, and an intensity of $17.8 \mathrm{~kW} / \mathrm{cm}^{2}$ for Figure 7(b). The higher magnification SEM micrograph of Figure 7(a) is shown in Figure 8. It is shown in Figures 7 


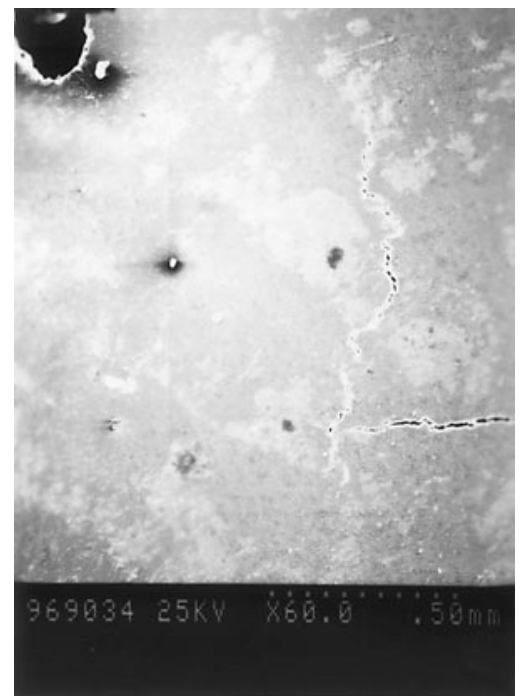

(a)

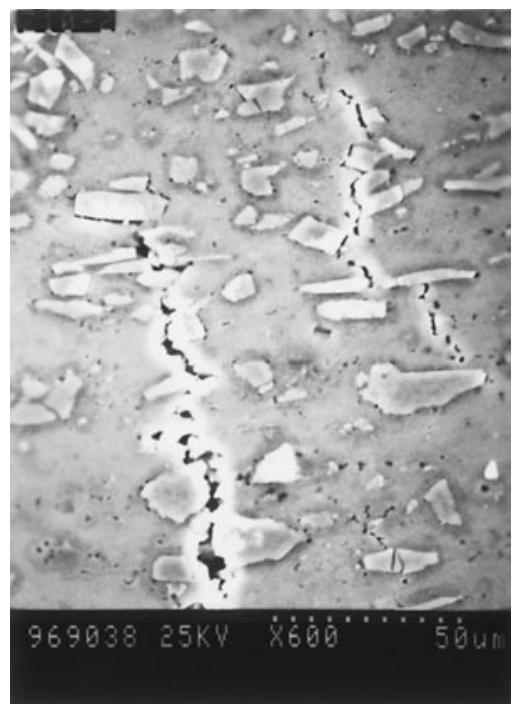

(b)

Fig. 6-(a) and (b) Radial crack showing voids in the matrix and separation of the $\mathrm{SiC}$ particle-matrix interface for sample 10 .

and 8 that reinforcement $\mathrm{SiC}$ particle fracture is the dominant damage mechanism. The reinforcements are broken by cracks perpendicular to the loading axis, and the fraction of broken reinforcements increases near the crack tip zone, as shown in Figure 9. Note that the SEM in Figure 9 is distinct from the SEM in Figure 6 in damage mechanism.

\section{Crack Propagation}

The presence of $\mathrm{SiC}$ reinforcement is typically detrimental to the fracture resistance of a composite material due to the addition of reinforcement fracture, reinforcement/matrix interface decohesion, and matrix failure and/or reinforcement decohesion and/or reinforcement fracture within the clusters to the failure mechanisms of the unreinforced aluminum alloy. Figure 8(b) shows the typical process of crack propagation. Arrow A in Figure 8(b) indicates the voids within the matrix that develop in the form of nucleation, growth, and coalescence. In this case, the fracture is ductile.

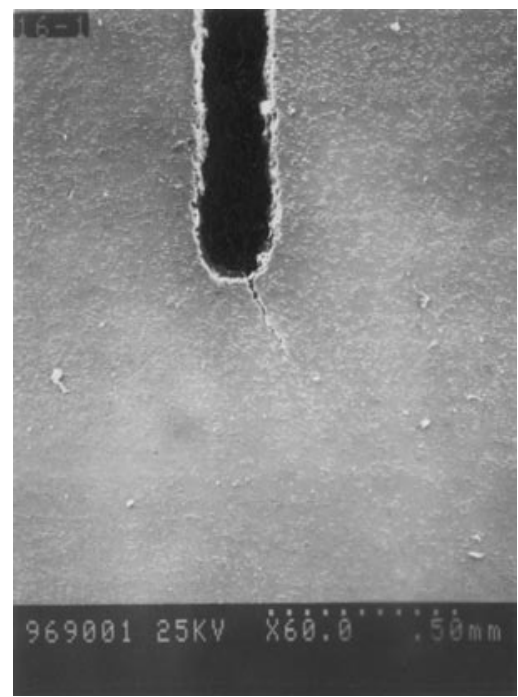

(a)

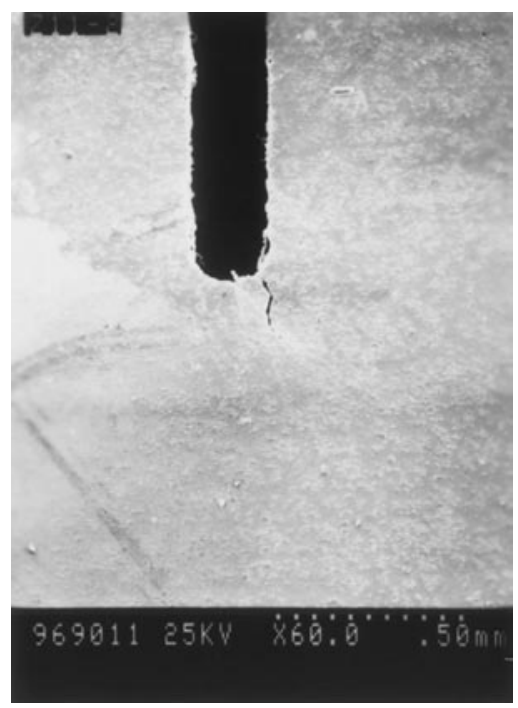

(b)

Fig. 7-SEM of macrocracks in the notched-tip region: $(a)$ laser energy is $3.13 \mathrm{~J}$ and FWHM is $1.0 \mathrm{~ms}$ for sample 6 and $(b)$ laser energy is 3.5 $\mathrm{J}$ and FWHM is $250 \mu \mathrm{s}$ for sample 11 .

Arrow B in Figure 8(b) indicates the fracture of the reinforcement $\mathrm{SiC}$ particle, and the main crack propagates through the fracture particle. In this case, the fracture is in the form of brittleness. Arrow C in Figure 8(b) indicates the voids associated with cavity nucleation by decohesion at the interface between the $\mathrm{SiC}$ particle and the matrix.

\section{DISCUSSION}

\section{A. Temperature Rise and Temperature Rise Rate}

Surface and internal temperatures in the composite materials can be determined by the diffusion:

$$
\rho C_{p} \frac{\partial \theta}{\partial t}=k\left(\frac{\partial^{2} \theta}{\partial r^{2}}+\frac{1}{r} \frac{\partial \theta}{\partial r}\right)+\frac{I(r, t)\left(1.0-R_{0}\right)}{h}
$$

where $r$ is the coordinate in the radial direction, $t$ is time, $\theta(r, t)$ is the temperature rise, and the reflection coefficient 


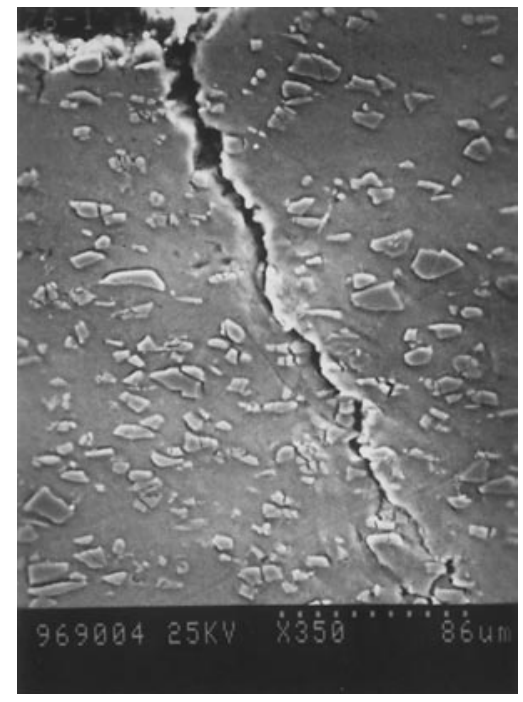

(a)

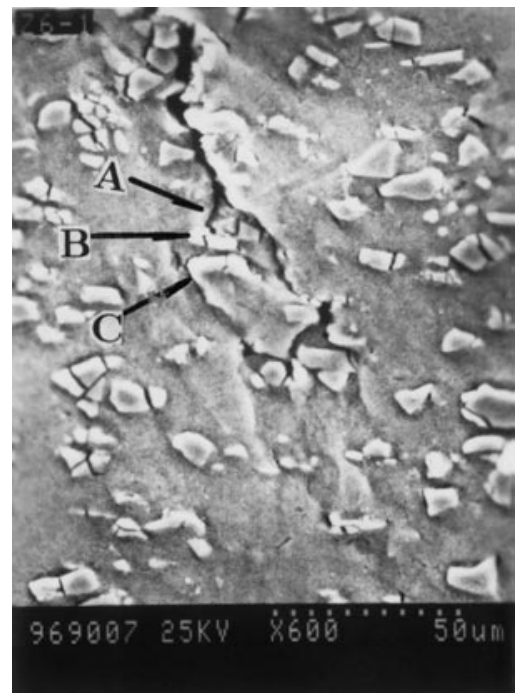

(b)

Fig. 8-(a) and (b) Enlargement of the photograph in Fig. 7(a) showing the cracked $\mathrm{SiC}$ particles.

$R_{0}$ is experimentally determined and equals 0.4 approximately. In formulas, $k, \rho, C_{p}$, and $h$ are the thermal conductivity, density, specific heat capacity of materials, and thickness of the plate, respectively. During the period of laser irradiating, the thermal conductivity effect can be ignored. Therefore, the temperature rise is approximately

$$
\theta=\frac{E_{J}\left(1-R_{0}\right)}{\pi \rho C_{p} h a^{2}}
$$

and the temperature rise rate is approximately

$$
\dot{\theta}=\frac{I(r, t)\left(1-R_{0}\right)}{\rho C_{p} h}
$$

From Table II, the temperature rise is $52.2{ }^{\circ} \mathrm{C}$ to $83.2{ }^{\circ} \mathrm{C}$ for $1.0 \mathrm{~ms}$ FWHM laser beam and $67.7^{\circ} \mathrm{C}$ to $107.8^{\circ} \mathrm{C}$ for $250 \mu$ s FWHM laser beam, respectively. The temperature rise rate is $5.22 \times 10^{4}{ }^{\circ} \mathrm{C} / \mathrm{s}$ to $8.32 \times 10^{4}{ }^{\circ} \mathrm{C} / \mathrm{s}$ for $1.0 \mathrm{~ms}$ FWHM laser beam and $2.70 \times 10^{5}{ }^{\circ} \mathrm{C} / \mathrm{s}$ to $4.30 \times 10^{5}{ }^{\circ} \mathrm{C} / \mathrm{s}$ for $250 \mu \mathrm{s}$ FWHM laser beam.

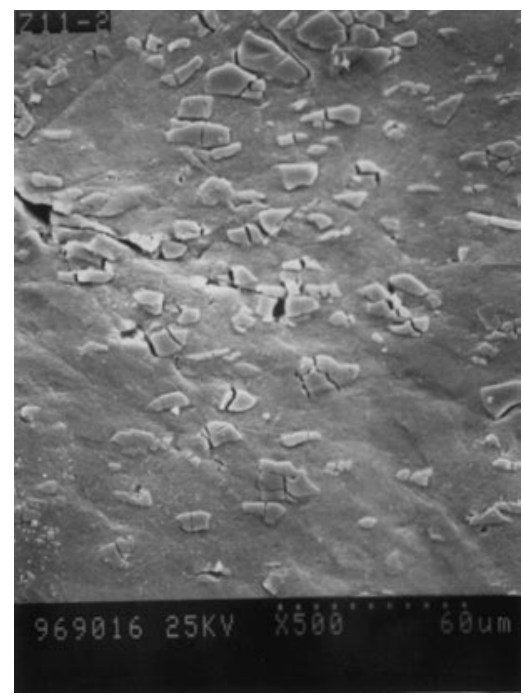

(a)

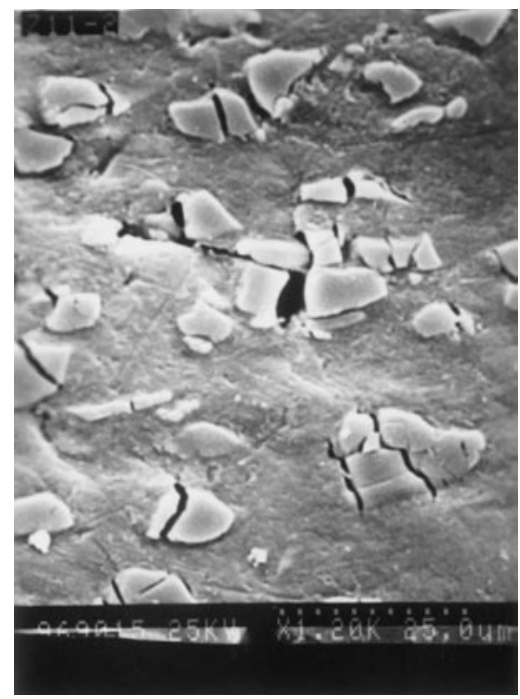

(b)

Fig. 9- (a) and (b) Phenomenon of SiC particles broken in the crack-tip region (sample 11).

\section{B. Thermal Mismatch Induced Deformation}

It is well known that the thermal or elastic constants are very different for the $\mathrm{SiC}$ ceramic and aluminum alloy. The material properties are given in Table I. It is noted that the mismatch in the thermal expansion coefficients between the matrix and the reinforcing phase is very large. In this case, changes in temperature lead to different deformations for the $\mathrm{SiC}$ particle and the metal matrix. The strain and strain rate of the $\mathrm{SiC}$ particle are, respectively, $2.24 \times 10^{-4}$ to $3.57 \times 10^{-4}$ and $0.224 / \mathrm{s}$ to $0.357 / \mathrm{s}$ for $1.0 \mathrm{~ms}$ FWHM laser beam. The strain and strain rate of the $\mathrm{SiC}$ particle are, respectively, $2.91 \times 10^{-4}$ to $4.63 \times 10^{-4}$ and $1.16 / \mathrm{s}$ to $1.85 / \mathrm{s}$ for $250 \mu \mathrm{s}$ FWHM laser beam. However, the strain and strain rate of aluminum alloy are, respectively, $1.23 \times$ $10^{-3}$ to $1.96 \times 10^{-3}$ and $1.23 / \mathrm{s}$ to $1.96 / \mathrm{s}$ for $1.0 \mathrm{~ms}$ FWHM laser beam. The strain and strain rate of aluminum alloy are, respectively, $1.6 \times 10^{-3}$ to $2.54 \times 10^{-3}$ and $6.37 / \mathrm{s}$ to $10.15 / \mathrm{s}$ for $250 \mu \mathrm{s}$ FWHM laser beam. The mismatch in the elastic constant between the matrix and the reinforcing 


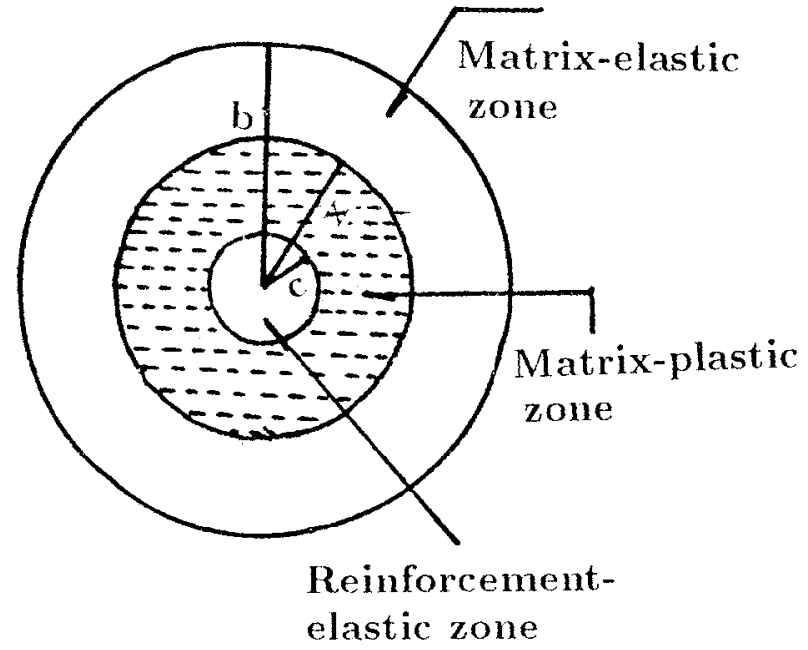

Fig. 10-Composite spherical approximation of the particulate-reinforced MMCs.

phase may induce the SiC particle to deform elastically and the matrix to deform plastically. This causes the localized residual deformation for matrix to be much larger than that for the $\mathrm{SiC}$ particle. In consequence of the local deformation around particles, it appears that the macroscopic surface has curvature. So we observed that the matrix around the $\mathrm{SiC}$ particles is polished in Figure 4(a) and the matrix around the $\mathrm{SiC}$ particles is rough in Figure 4(b).

\section{Damage Initiation}

Thermal shock is generated by irradiation of the center of the sample. The spatial profile of temperature distribution is influenced definitely by the spatial shape of the laser beam. Therefore, different spatial shapes of laser beam lead to different temperature distributions, even though the net energy and duration are the same. For a non-Gaussian type laser, as shown in Figure 2 or indicated by Eq. [2], the spatial distribution of the temperature is uniform within the laser irradiated region and declines very sharply toward the edge, where the laser spot terminates. ${ }^{[13]}$ This means that temperature at the center of the specimen is much high than that at the outer rim. The induced higher thermal expansion in the sample center is constrained by the cooler edge, causing tensile hoop stresses at the edge and tangential and radial compressive stresses in the center. The thermal stresses satisfy the conditions of force and momentum equilibrium. The linear elastic solution for radial and tangential thermal stresses $\sigma_{r r}(r, t)$ and $\sigma_{\theta \theta}(r, t)$ has the following form:

$$
\begin{gathered}
\sigma_{r r}=-\frac{\sigma E}{r^{2}} \int_{0}^{r} \theta(\xi, t) \xi d \xi \\
\sigma_{\theta \theta}(r, t)=\alpha E\left[\frac{1}{r^{2}} \int_{0}^{r} \theta(\xi, t) \xi d \xi-\theta(r, t)\right]
\end{gathered}
$$

where the Young's modulus and thermal expansion coefficient are denoted by $E$ and $\alpha$, respectively.

Therefore, as shown in Figure 6, the radial crack is induced by the tensile hoop stresses $\sigma_{\theta \theta}$ at the edge when the laser heating region is deviated from the notched-tip region (Figure 3(c)). Also, as the notched-tip region is subjected to laser beam heating, the tensile hoop stresses coupled with the far-field mechanical loading cause the stress concentration in the notched-tip region. As shown in Figure 5, the initial damage takes place in the notched-tip region. One can conclude that microcracking may appear without the notch stress intensity. However, the notch is necessary to provide a microcrack path for formation of a macrocrack and drives crack propagation.

\section{Mechanism of Crack Formation and Propagation}

As previously described, the initial crack is produced by the mechanism of void formation in the matrix and separation of the $\mathrm{SiC}$ particle-matrix interface, while the crack propagation is dominated by $\mathrm{SiC}$ particle fracture. Why is there a difference between the damage mechanism for crack formation and crack propagation?

It is well known that the reinforcement of a hard ceramic in a soft metallic matrix produces composites with substantially higher yield strength compared to that of the matrix. In earlier investigations, the strengthening effect is primarily attributed to two factors. Nardone et al. ${ }^{[18,19]}$ proposed a modified shear lag (MSL) model based on the shear lag theory, ascribing the entire strengthening effect to the load bearing feature of the hard reinforcement. On the other hand, Arsenault et al. ${ }^{[20]}$ mainly attributed the strengthening to the enhanced strength of the matrix effected by the increase in the dislocation density in the matrix by a few orders of magnitude.

The composite sphere, in its most general form, is assumed to comprise three zones (Figure 10): elastic reinforcement, surrounding matrix plastic, and outer elastic. According to the MSL theory, a tensile radial stress $\sigma_{r r}$ is generated at the interface of an elastic inclusion in a plastic zone (Figure 10), and it is developed across the interface, which is given by ${ }^{[21,22]}$

$$
\sigma_{r r} \sim \sigma\left(\varepsilon_{p}\right)+\sigma_{T}
$$

where $\sigma\left(\varepsilon_{p}\right)$ is the matrix yield stress at the plastic strain loading attained adjacent to the particle, and $\sigma_{T}$ is any tensile hydrostatic stress developed in the neighborhood of the particle.

On the other hand, ceramic reinforcements, when incorporated into aluminum matrices, can introduce flaws into the matrix and premature failure of the composites. ${ }^{[23,24]}$ The flaws can cause significant stress concentrations and local biaxial or triaxial stresses in the vicinity of the defect; the magnitude of the stress at the crack tip is highly dependent on geometry. The applied stress, defect size, and geometry are often related by the equation

$$
K_{I}=Y \sigma_{r r} \sqrt{\pi c}
$$

where $K_{I}$ is the stress intensity factor in mode I, $\sigma_{r r}$ is the applied stress, $c$ is the depth of penetration of the surface crack, and $Y$ is a constant that depends on the crack opening mode and crack shape.

So far, when $K_{I}$ is less than $K_{I c}$, which is a constant of reinforcement material and a measure of fracture toughness, the $\mathrm{SiC}$ particles do not fracture and either the matrix or the interface of particle-matrix may fail for the large localized stresses. When the MMCs are subjected to laser beam heating, the strength of the matrix will be degraded at el- 
evated temperatures. In other words, the matrix yield stress $\sigma\left(\varepsilon_{p}\right)$ decreases. In this case, the particle loading through the interface, $\sigma_{r r}$, is so low that the $\mathrm{SiC}$ particle cracking does not take place. But the localized thermal stresses due to the rapid changes in temperatures may lead to the nucleation of microcracks within the matrix/reinforcing phase interface or in the matrix. More commonly, however, these thermal stresses lead to the growth of pre-existing cracks. If the applied stress is sufficiently large, these microcracks may grow into macroscopic cracks and lead to the propagation of the macrocrack.

As we know, the strain rate at the crack tip is very high in the case of macrocrack propagation. As a result of the high strain rates or the matrix hardening, the matrix yield stress $\sigma\left(\varepsilon_{p}\right)$ increases significantly. Equivalently, the tensile radial stresses $\sigma_{r r}$ are so high that the stress intensity factor $K_{I}$ may exceed the $\mathrm{SiC}$ particle strength, i.e., the Griffith criterion.

In brief, the difference in the damage mechanism between crack formation and crack propagation is due to the matrix degradation or the matrix hardening.

\section{SUMMARY}

The thermal failure of SiC-particle-reinforced 6061-Al matrix is studied. The threshold intensity for the laser beam thermal shock loading coupled with the far-field tensile stresses causing the MMC fractures is measured. Also, the thermal shock behavior of MMCs is determined via the macroscopic and microscopic observation of the crack-tip process zone development and the initial microcrack formation. It is shown that in these materials, the initial crack occurs in the notched-tip region, wherein the initial crack is induced by either the void nucleation, growth and subsequent coalescence of the matrix materials, or separation of the $\mathrm{SiC}$ particulate-matrix interface. It is further found that the process of the crack propagation occurs by the fracture of the $\mathrm{SiC}$ particulate. The difference in damage mechanism between the crack formation and crack propagation is discussed. It is proposed that at the early stage of laser irradiating the low yield stress of the matrix induces the particle loading to be low and the voids appear in the matrix or within the interface of the particle/matrix. Once the microcracks grow into macroscopic cracks, the hardening of the matrix due to the high strain rate in the case of macrocrack propagating causes high particle loading that exceeded the particle strength and causes the particle to fracture.

\section{ACKNOWLEDGMENTS}

Support for this research program was provided partly by the NNSF of China and partly by the Field of Laser
Technology, 863-NHT Research Development Program. The research program is also supported by the Education Commission of the Hunan Province. This support is fully appreciated. The authors show their sincere gratitude to the referees for their careful proofreading and many valuable suggestions.

\section{REFERENCES}

1. D. Charles: Met. Mater., 1990, vol. 6, pp. 78-82.

2. N. Ramakrishnan: Acta Mater., 1996, vol. 44, pp. 69-77.

3. B. Wang, G.M. Janowski, and B.R. Patterson: Metall. Mater. Trans. A, 1995, vol. 26 A, pp. 2457-68.

4. C.W. Nan and D.R. Clarke: Acta Mater., 1996, vol. 44, pp. 3801-11.

5. J.W. Luster, M. Thaumann, and R. Baumann: Mater. Sci. Technol., 1993, vol. 9, pp. 853-62.

6. M. Taya and K.E. Lulay: Acta Metall. Mater., 1991, vol. 39, pp. 7387.

7. S.V. Nair, J.K. Tein, and R.C. Bates: Int. Met. Rev., 1985, vol. 30, pp. 275-90.

8. P. Berlin, O. Dickman, and F. Larsson: Composites, 1992, vol. 23, pp. 235-43.

9. Y.C. Zhou, Z.P. Duan, and B.M. Xie: Int. J. Eng. Sci., 1997, vol. 35, pp. 613-21.

10. N. Noda and Z.H. Jin: Int. J. Solid Struct., 1993, vol. 30, pp. 103956.

11. J.W. Nichols and S. Mall: Eng. Fract. Mech., 1989, vol. 32, pp. 78794.

12. Y.C. Zhou, C.K. Wang, and Z.P. Duan: High Power Laser and Particle Beams, 1995, vol. 7, pp. 350-54.

13. Y.C. Zhou, Z.P. Duan, and Q.B. Yang: Int. J. Solid Struct., 1997, in press.

14. K.A. Hartley, J. Duffy, and R.H. Hawley: J. Mech. Phys. Solids, 1987, vol. 35 , pp. 283-301.

15. A.T. Zehnder and A.J. Rosakis: J. Mech. Phys. Solids, 1991, vol. 39, pp. 385-415.

16. S. Elomari, R. Boukhili, and D.J. Lloyd: Acta Mater., 1996, vol. 44, pp. 1873-82.

17. D.L. Davidson: Metall. Trans. A, 1991, vol. 22A, pp. 97-112.

18. V.C. Nardone and K.M. Prewo: Scripta Metall., 1986, vol. 20, pp. 43-48.

19. V.C. Nardone: Scripta Metall., 1987, vol. 21, pp. 1313-18.

20. R.J. Arsenault, L. Wang, and C.R. Feng: Acta Metall. Mater., 1991, vol. 39 , pp. 47-57.

21. R.D. Thompson and J.W. Hancock: Int. J. Fract. Mech., 1984, vol. 24, pp. 209-28.

22. D.J. Lloyd: Acta Metall. Mater., 1991, vol. 39, pp. 59-71.

23. P.M. Singh and J.J. Lewandowsk: Metall. Trans. A, 1993, vol. 24A, pp. 2531-43.

24. S.G. Song, R.U. Vaidy, A.K. Zurek, and G.T. Gray III: Metall. Mater. Trans. A, 1996, vol. 27A, pp. 459-65.

25. D.J. Nans, G.B. Batson, and J.L. Lott: Fracture Mechanics of Ceramics, Plenum Press, New York, NY, 1974, vol. 2, p. 489.

26. Q.F. Ma, R.S. Fang, L.C. Ciang, and S. Guo: Handbook of Thermophysical Properties of Matter, Chinese Agricultural Machinery Press, Beijing, 1986 (in Chinese).

27. Y.C. Zhou, Z.P. Duan, and Q.B. Yang: Int. J. Non-Linear Mech., 1997 , in press.

28. Y.C. Zhou, Z.P. Duan, B.M. Xie, C.G. Huang, and Z.X. Yang: Acta Mech. Sinica, 1995, vol. 27, pp. 277-93. 